\title{
Atletas de base de futebol: a experiência de viver em alojamento
}

\author{
Rodrigo Lourenço Salomão - Psicólogo \\ Giovanna Pereira Ottoni - Universidade de São Paulo, Ribeirão Preto, Brasil \\ Cristiano Roque Antunes Barreira - Universidade de São Paulo, Ribeirão Preto, Brasil
}

\begin{abstract}
Resumo
Situado na Psicologia do Esporte, o objetivo desta investigação foi identificar e compreender o horizonte de experiências vivenciadas por jovens, na condição de atleta de base de time de futebol morando em alojamento do clube. Foram entrevistados 19 jogadores da categoria sub-17 na primeira divisão dos campeonatos paulista e mineiro. A arqueologia fenomenológica das culturas referencia metodologicamente a análise que deu acesso às vivências determinantes da situação estudada. Existencialmente, as vivências individuadas interpenetram-se configurando a percepção dos jogadores. O balanceamento e norteamento das mesmas é modulado especialmente pelo sentido do projeto de cada jogador e pelo empenho nele depositado. No contato com a dimensão do projeto existencial é que a atuação do psicólogo joga seu papel ético nesse delicado contexto de transição. Palavras-chave: Psicologia do esporte; Psicologia fenomenológica; Futebol; Projeto de vida.
\end{abstract}

\section{Base athletes of soccer: the experience of living in the Club dorms}

\begin{abstract}
Located in the Sport Psychology, the aim of the inquiry was to identify and understand the horizon of experiences lived by young people as base athletes of soccer teams living in the Club dorms. 19 players of category sub-17 in the first division of the Paulista and Mineiro Championship were interviewed. The phenomenological Archaeology of cultures methodologically refers to the analysis which gave access to determinant experiences of the situation under study. Existentially, the individual experiences interpenetrate themselves shaping the perception of the players. The counterbalance and guidance of such experiences are modeled especially by the sense of the project of each player and by the endeavor put in him. In this delicate context of transition, is through the contact toward the dimension of the existential project which the performance of the psychologist plays his ethical role.

Keywords: Sport Psychology; Phenomenological Psychology; Soccer; Life project.
\end{abstract}

\section{Los atletas de fútbol de base: la experiencia de vivir en un alojamiento}

\begin{abstract}
Resumen
Ubicado en la Psicología del Deporte, el objetivo de la investigación fue el de identificar y comprender el horizonte de experiencias vivenciales de jóvenes en la condición de atleta de base de equipo de fútbol viviendo en alojamiento del Club. Fueron entrevistados diecinueve jugadores pertenecientes a la categoría de los diecisiete años en la primera división del campeonato "Paulista" y "Mineiro". La arqueología fenomenológica de las culturas menciona metodológicamente el análisis que dio acceso a las vivencias determinantes de la situación estudiada. Las vivencias individuales se mezclan configurando la percepción de los jugadores. El balance y el norte de las mismas es modulado especialmente por el sentido del proyecto de cada jugador y por el empeño en él depositado. En este delicado contexto de transición, es en el contacto con la dimensión del proyecto existencial que la actuación del psicólogo juega su papel ético.

Palabras-clave: Psicología del deporte; Psicología fenomenológica; Fútbol; Proyecto de vida.
\end{abstract}

\section{Introdução}

Este trabalho aborda a percepção de atletas acerca de sua condição num contexto bastante específico e decisivo no que tange à transição de carreira: aquele em que jogadores de categorias de base de futebol estão vivendo no alojamento de seus clubes. Ainda pouco abordado pela literatura (Barros, 2008), a transição de carreira esportiva é um tema relativamente atual em psicologia, com implicações para uma prática clínica ampliada. Trata-se de uma investigação pertinente à psicologia, do esporte, que, apesar de possuir cerca de um século de história, ainda é considerada emergente no Brasil (Rubio, 2007).
A psicologia do esporte e do exercício pode ser definida como o "estudo científico de pessoas e seus comportamentos em atividades esportivas e atividades físicas e na aplicação prática desse conhecimento" (Weinberg \& Gould, 2008, p. 22). Desse modo, visto que este trabalho se interessa pela percepção de atletas acerca de sua condição num contexto específico, volta-se à dimensão pessoal dos mesmos, isto é, a sua subjetividade, esquivando-se, em contrapartida, de cumprir uma abordagem que isole a ação comportamental do jogador.

Essas considerações preliminares sobre a abordagem são relevantes à medida que a psicologia do 
esporte tem se desenvolvido como importante campo de pesquisa e atuação, sendo conhecida hegemonicamente pelas perspectivas comportamentais (Nesti, 2011). Entretanto, a psicologia convive em recorrentes polêmicas acerca das diversas formas de pensar o que se poderia definir como psicológico. Numa orientação que amplie qualitativamente o horizonte das considerações acerca do esporte - seja em relação às dimensões sociológicas, seja em relação às antropológicas ou psicológicas - o caso do futebol, especialmente, comparece como um fato social total (Costa, 2005), que contribui para uma possível compreensão do mundo contemporâneo. Todavia, para além do reconhecimento de seu caráter global, é um fenômeno que merece ser estudado em todas as suas facetas, incluindo aquela que diz respeito à dimensão psíquica, de modo a levar em conta direta e particularmente seus jogadores, inclusive os que almejam ser profissionais (Rubio, 2007).

No meio esportivo a desconfiança vem emoldurada pelo espetáculo, pela possibilidade de ascensão social diante da falta de oportunidades, pela fama e fortuna decorrentes da superação acompanhada de valores físicos e sociais de grande força histórica, ética e moral (Pereira, 2008). Este aspecto, pode-se dizer, ostensivo do futebol enquanto fato social total, reproduz um modelo esportivo que, conforme acusam Cavalli e cols. (2007), "tende a considerar e abordar as crianças e jovens como se fossem adultos em miniatura" (p. 248). Imersos neste contexto, os jovens envolvem-se num processo imaginário relativo ao modelo de valores hegemônicos. É neste registro imaginário que, implícito em condutas esportivas e projetos pessoais, pode-se reconhecer a ostensividade do contexto presente na singularidade pessoal de jovens atletas a partir do trabalho em psicologia. Cavalli e cols. (2007) alertam para a questão sociopedagógica referente à opção esportivo institucional de se realizar "uma cópia dos padrões adotados pelos adultos" (p.248), cujas implicações não são bem conhecidas.

Sem a pretensão de compensar as implicações dessa questão socioeducativa, este trabalho se volta à compreensão psicológica da condição de jovens jogadores de categorias de base que, além de inseridos nesse contexto complexo, vivem em alojamentos de clubes de futebol. É em relação a esse recorte contextual que surgem as experiências tematizadas neste estudo. Cabe ressaltar, ainda, que a condição específica do jovem - uma vez que este se encontra numa fase do ciclo de vida na qual a vulnerabilidade, o anseio pela preparação e a futura colocação profissional, tão importantes na formação de sua identidade (Guardini, 1987) - situa o modo como comparece seu projeto de vida como esportista.

$\mathrm{Na}$ dinâmica psíquica entre identidade e projeto, não só as oportunidades de êxito estarão presentes, mas também as decepções e frustrações, acompanhadas de inevitável sofrimento. Como lembra Mauro Maldonato, "o discurso sobre a identidade impossibilita tanto a designação de confins estáveis, quanto palavras definitivas" (2014, p. 16). Assim, sem demarcar confins estáveis, numa descrição breve e fenomenologicamente suficiente, identidade consiste numa imagem de si a que o sujeito julga corresponder. $\mathrm{Na}$ distância entre a imagem e sua correspondência, pela qual um juízo se preenche de múltiplos afetos possíveis, como desejo ou desprezo, reside um componente psíquico decisivo existencialmente. Assim, por exemplo, a distância de um ideal de si e a proximidade com uma imagem depreciada de si é vivenciada como vergonha (Kalrsson e Sjöberg, 2009); a proximidade com uma imagem positivamente idealizada de si, com distanciamento do que se deprecia, é vivenciada como orgulho. O projeto, então, é aquilo que lança o sujeito na direção de uma imagem positiva de si mesmo ainda situada no porvir, exigindo seu empenho, a fim de se avizinhar dela.

As preocupações e questões que delimitam os interesses pela experiência vivida do atleta juvenil de morar em alojamento do clube de futebol, encontram ressonância junto à temática mais geral da transição de carreira. No esporte, a transição de carreira implica as várias etapas ultrapassadas por atletas durante seu desenvolvimento e histórico na modalidade esportiva (Carlin \& Ruiz, 2012).

Segundo Wylleman, Alfermann e Lavallee (2004), esses atletas enfrentam determinadas experiências durante esse período que provocam grandes alterações no seu curso de vida. Essas alterações acarretam uma mudança na concepção de si mesmo ilimitada à modificação do cotidiano. No mesmo estudo, os autores afirmam haver modificação nas atitudes e no seu modo de pensar, destacando esses aspectos na etapa inicial da transição de carreira.

$\mathrm{Na}$ mesma direção, Henriksen, Stambulova e Roessler (2010) descrevem um modelo de desenvolvimento de carreira - e as transições presentes durante esse período - como um processo que perpassa por várias transições, desde o seu início até a aposentadoria. Carlim \& Ruiz (2012) também contemplam a transição considerando as várias etapas ultrapassadas por atletas durante seu desenvolvimento e histórico na modalidade esportiva. 
Barros (2008) ressalta que já no momento em que o indivíduo adota como objetivo tornar-se atleta, já é iniciada uma transição. Em outras palavras, a transição, já nesta fase inicial, prenuncia exigências específicas que requerem um ajustamento no meio financeiro, ocupacional, social e psicológico (Brandão e cols., 2000). Posteriormente, no momento em que o atleta se depara com as realidades e adversidades próprias ao envolvimento com o esporte em que irá se profissionalizar, há uma natural adaptação ao novo meio social, bem como à nova condição pessoal em que se encontra.

Esquivando-se de uma enumeração de fatores objetivos que caracterizam a transição, a psicologia de perspectiva fenomenológica, adotada no presente trabalho, embora permita acessar resultados que dialoguem com as teorias acima resumidas, não parte de quaisquer de seus resultados, mas, de modo independente, efetiva sua suspensão para privilegiar em seu lugar a própria experiência dos atletas. Por não consistir numa teoria psicológica, mas numa perspectiva metodológica compreensiva, a operatividade de seus conceitos visa, essencialmente, descerrar o acesso aos fenômenos para que estes venham à tona possibilitando sua descrição. Com enfoque na experiência de iniciação no esporte, a problemática da pesquisa não pode ser reduzida a uma coleção de fatores objetivos, como já se mencionou. Isso porque a perspectiva experiencial implica posicionamentos presentes enquanto registro da subjetividade, ou seja, relativos à historicidade de cada pessoa.

Trata-se de uma análise fenomenológica da consciência intencional, o que consiste em uma passagem conceitual fundamental para se avançar rumo ao momento empírico do processo de investigação fenomenológica em psicologia. Consciência intencional denota o mais elementar sentido de consciência, segundo o qual esta não é uma coisa, mas é sempre consciência de alguma coisa. Para conhecer um fenômeno, portanto, é necessário desvencilhar-se de teorias e explicações que mediam o acesso da consciência ao mesmo e descrevê-lo tal e qual se manifesta à consciência (Husserl, 2006).

Tal consideração não significa, contudo, que a compreensão da condição em que esses jovens se encontram deva corresponder apenas à dimensão singular, mas também àquilo que há de comum no que tange à condição vivida, tornando possível apreender o próprio horizonte de possibilidades essenciais no qual esses atletas estão inseridos (Ottoni, Ranieri \& Barreira, 2008).

Colocado isso, a presente investigação tem como objetivo compreender, inscrevendo-se no método fenomenológico, as experiências vividas por atletas da categoria de base de um time de futebol morando no alojamento disponibilizado pelo próprio time. Pretende-se apreender sob tal perspectiva, em termos genéricos e a partir de suas próprias experiências, o modo como atletas nessa condição encontram e vivenciam seu meio. Esses resultados estão potencialmente voltados ao trabalho dos profissionais de psicologia do esporte a fim de, no contexto institucional dos clubes, contribuir para o encaminhamento de intervenções adequadas e socialmente responsáveis às demandas existenciais vividas por esses jovens.

\section{Método}

\section{Participantes}

Foram entrevistados dezenove atletas da categoria sub 17 que se encontravam morando em alojamento do próprio clube de futebol ao qual pertenciam. As equipes estavam na primeira divisão, sendo duas do campeonato paulista e uma do campeonato mineiro. A amostra foi composta de doze atletas dos clubes paulistas e sete jogadores do clube mineiro. A caracterização de cada atleta em relação à classe socioeconômica e à história de vida não aparece como necessária para os resultados expostos no presente artigo, uma vez que se buscou a essência da experiência vivida.

\section{Instrumentos}

\section{A perspectiva metodológica.}

A Fenomenologia clássica se coloca no âmbito das metodologias qualitativas em psicologia e se propõe como perspectiva filosófica que, enquanto tal, sistematiza um caminho de reflexão rigorosa sobre a experiência humana. Trata-se particularmente da proposta apresentada por Ales Bello (1998) e Mahfoud e Massimi (2013) como arqueologia fenomenológica das culturas, cujo escopo é de identificar e descrever os sentidos que constituem essencialmente o objeto estudado.

A análise fenomenológica direciona-se à experiência dos sujeitos conforme trazida em primeira pessoa nos relatos colhidos, o que a caracteriza como "do tipo intencional, partindo daquilo que se manifesta pelo relato" (Ottoni, Ranieri \& Barreira, 2008, p. 12). Isso quer dizer que ele deve focar seu interesse nas experiências vivenciais, lançando luz ao fenômeno a ser estudado a partir dos fatos específicos que os sujeitos relatam, visando apreendê-lo na maneira com que aparece para aquele que a vive. Portanto, visa-se ultrapassar 
uma descrição dos fatos enquanto experiência empírica pertencente ao mundo da natureza para que seja possível apreender o sentido que lhe confere a consciência dos sujeitos que os vivenciam.

A partir das entrevistas, seguem-se leituras e releituras das mesmas com o intuito de identificar os pontos essenciais que se mostram definindo os sentidos que compõem a experiência de morar em alojamento para esses atletas. "A tematização e a modalização que acomunam estes pontos permitem a formação de diferentes categorias, as quais precisam, contudo, ser compreendidas na unidade do horizonte das percepções acessadas, isto é, em sua dinâmica e não como partes isoladas do todo" (Ottoni, Ranieri \& Barreira, 2008, p. 12-13). Com isso, não basta apenas retratar a experiência, mas se voltar aos elementos sobre os quais ela se funda e se torna apreensível, querendo desvelar a plenitude do fenômeno particular que, ao se mostrar, encontra-se em seu horizonte de possibilidade (Karlsoon \& Sjöberg, 2009).

\section{Entrevista fenomenológica}

As entrevistas foram de cunho fenomenológico e consistiram num processo de conversação dialógica em que a conduta do entrevistador direciona a abordagem de uma temática a partir do registro de uma narrativa expressiva da experiência vivida pelo entrevistado (Barreira \& Ranieri, 2013). As questões norteadoras foram: I- Como você viveu sua história no esporte até morar aqui no alojamento? II- Como está sendo pra você morar aqui no alojamento? III- A partir desta experiência que você vive aqui no alojamento, o que você espera? Ressalta-se que para sua realização foi "imprescindível ao entrevistador notar sensivelmente, durante a entrevista, os 'pontos fortes', a fala autêntica (Amatuzzi, 2001), isto é, aquilo que está atrelado à experiência vivida e aos momentos significativos, voltando-se aos mesmos e buscando aprofundamento e a interação com o 'mundo privado do sujeito"' (Ottoni, Ranieri \& Barreira, 2008, p. 11) no que se refere ao objeto estudado.

\section{Procedimentos}

1. Após a assinatura de um termo de consentimento livre e esclarecido, adequado aos cuidados éticos para este tipo de pesquisa, utilizaram para coleta dos dados, entrevistas semi estruturadas que foram gravadas em áudio e transcritas na íntegra. As identidades dos atletas foram preservadas e as entrevistas só ocorreram após o contato com o clube, a autorização da diretoria e dos responsáveis legais para a participação dos sujeitos entrevistados, bem como o livre consentimento dos próprios. 2. Análise fenomenológica: realizou-se o cruzamento intencional a partir da chamada redução fenomenológica (Barreira \& Ranieri, 2013). A redução se funda no exercício de reflexão sistemática, que tem como enfoque o fenômeno na forma como se mostra nos relatos, subtraindo (reduzindo) conceitos, ideias e julgamentos prévios sobre o mesmo. Após explicitar os sentidos atribuídos pela experiência pessoal de cada participante, passa-se ao cruzamento intencional que se apoia na comparação entre todas as entrevistas, de modo a permitir evidenciar os sentidos comuns nelas presentes enquanto vivências constituintes do fenômeno (Barreira \& Ranieri, 2013). A redução e o cruzamento buscam, portanto, descrever a correlação entre o objeto da experiência e a vivência deste mesmo objeto, tomando-a através da experiência vivida.

\section{Resultados}

Com base nos relatos dos sujeitos e em sua análise, tornou-se possível descrever um horizonte de experiência essencial desses jogadores. Este horizonte compôs-se através das unidades de sentido, ou categorias, que, como já dito, perpassaram as entrevistas individuais, mas não correspondem a nenhuma delas factualmente. Essas categorias descrevem, portanto, sentidos psicológicos que as atravessam e as estruturam de modo essencial, sendo comuns à experiência pré-reflexiva que situa todos os atletas que se encontram nesta condição.

\section{Brincadeira X Seriedade}

O futebol está inserido amplamente na sociedade brasileira, independentemente da diversidade cultural, financeira e social presente no país. Com isso, a maioria dos garotos costuma praticar o futebol ainda criança. Esse é um fato que ocorreu com os atletas abordados na pesquisa. A entrada no primeiro clube é relatada como uma espécie de continuação da brincadeira, mas que começava a transformá-la. Com o passar do tempo, as exigências do contexto do clube vão modificando sua posição em relação ao que é jogar futebol. Inicia-se um processo de predominância da seriedade, em função dos compromissos e regras do clube que precisam ser atendidos. Por outro lado, a brincadeira segue fazendo parte de jogar e cada atleta parece viver uma negociação para regular os momentos de seriedade e de brincadeira. Trata-se de um processo que eles nomeiam como aprendizagem: "aprender a hora de brincar e a hora de trabalhar sério". A alternância entre brincadeira 
e seriedade é vivenciada por eles de maneira peculiar e individual. Em meio às particularidades das trajetórias de vida de cada atleta, esse elemento comum corresponde a uma tensão, que gradualmente se acirra, entre posturas pessoais e demandas no mundo do futebol.

Os polos presentes nesta categoria aparecem na experiência dos jogadores na forma das situações em que primeiramente se dão conta da necessidade de comprometimento e, com essa demanda, da escolha entre apenas jogar futebol ludicamente ou começar a aceitar e adotar as responsabilidades próprias a jogar num clube. Comumente, essas situações iniciais acontecem já nas escolinhas de futebol, antes mesmo, portanto, de passarem a morar nos alojamentos dos clubes. Independentemente de suas histórias de vida, aspectos socioeconômicos e pessoais, essa escolha é crucial para que esses atletas assumam um projeto de vida que contemple a carreira esportiva como meta. Embora a escolha pela "seriedade" seja essencial a essa experiência, já que qualquer atleta que não a tivesse realizado não entraria na amostra intencional, não se deve presumir que, uma vez realizada, os jogadores deixem de se debater com a questão. De fato, nota-se que essa tensão é permanentemente constitutiva da experiência de jovens atletas que ainda não se firmaram profissionalmente na carreira, mas esperam fazê-lo, permeando toda a experiência vivida. $\mathrm{O}$ resultado predominante dessa tensão é uma espécie de alicerce do projeto de carreira esportiva ou de seu abandono.

Do ponto de vista empírico, essa polarização aparece na comparação entre a assunção do futebol como profissão potencial (na pré-adolescência de todos os entrevistados) e o jogo infantil, nos momentos em que futebol era apenas uma atividade lúdica, sem perspectivas profissionalizantes. Enquanto vivência, a brincadeira tem o caráter da leveza própria a uma atividade espontânea e prazerosa. Essa vivência entra em tensão com a seriedade do comprometimento com um clube de futebol e a expectativa de futura profissionalização. As demandas de comprometimento com horários, treinos, esforços e sacrifícios, como a saída de casa, tornam a experiência, que antes era predominantemente lúdica, carregada. O trecho de relato a seguir ilustra a situação: "Ah, com nove anos eu levava mais mesmo só como diversão e tal, lazer, mas com o tempo, igual hoje, eu levo mesmo como trabalho" (A17). A leveza compete com a vivência do peso da seriedade, com sua rotina e exigência de postura pautada no modelo de conduta profissional. Empiricamente, mesmo quando o futebol deixa de ser visto como brincadeira para se tornar "coisa séria", a modulação da leveza emerge nas várias brincadeiras próprias à convivência no alojamento e também ao jogo em si. Morando no alojamento e ante a Dificuldade de estar fora de casa (próxima unidade de sentido), a leveza das brincadeiras aparece como distração fundamental para a condição de relativo sofrimento na qual se encontram, assim como favorece o estabelecimento de vínculos entre os jovens. Outro relato ilustra essa condição:

\begin{abstract}
... a gente tem o momento de trabalhar, que é momento que a gente treina, e tem o momento de brincar de se descontrair, que é o momento que a gente está na concentração e brinca e zoa e tal. A gente leva tudo numa boa; seriedade quando a gente está trabalhando lá no campo...(A19)
\end{abstract}

A negociação psicológica do tempo e espaço pertinentes à brincadeira e à seriedade, bem como das condutas adequadas aos ideais de profissionalização e às condições de enfrentamento do sofrimento, acompanham os jovens desde sua entrada no clube e se projetam também no futuro profissional almejado, sendo a figura central de compreensão dessa fase de transição de carreira. Aqui, abraçar a seriedade corresponde a abraçar o projeto de profissionalização. A brincadeira e a negociação com a seriedade, no entanto, farão parte da experiência dos atletas ao longo de toda sua carreira.

\section{Dificuldade de estar fora de casa}

Essa experiência diz respeito à saída de casa dos atletas e à maneira como eles experimentam essa mudança na própria vida, pelo distanciamento do cotidiano familiar e doméstico. Nota-se que esse fenômeno ocorreu independentemente das várias diferenças entre os jogadores, por exemplo, a idade em que saem de casa, indo dos doze aos dezesseis anos, a configuração familiar e o círculo de amizade, status social e financeiro. Trata-se de uma dificuldade que se apresenta para todos e, apesar das particularidades existenciais, uns com sofrimento maior em relação à saudade, outros com a diversidade de cultura e de costumes encontrados no alojamento. Sempre há um sofrimento essencial à experiência de estar fora de casa, qual seja, a vivência de uma falta que demanda "compensação". Como se verá, essa compensação parece encontrar um lugar no presente, mas é no futuro, na compensação por meio do que ainda virá, que os jovens jogadores depositam suas esperanças para enfrentá-la.

Longe do lar, tomar conta de si próprio surge como um aspecto importante. Lar, aqui, representa o 
seu lugar de origem, com todos os objetos, pessoas e experiências típicas da sua moradia. Modifica-se a organização cotidiana da vida do atleta, organização na qual se deixa de contar com auxílios e costumes estabelecidos para se ter que assumir novas funções e tarefas do cotidiano. Um atleta relata isso muito bem quando diz:

Tipo, lá em Ribeirão, na minha cidade, eu estava acostumado a outros costumes, outras coisas, ai eu vim pra cá sabe, ai não tem como... tipo, minha mãe me levar pros lugares, essas coisas, e aqui eu tenho que me virar sempre, ai tipo foi maior mudanca na minha vida isso e agora eu tenho que me virar sozinho. (A15)

O enfrentamento dessa situação, para alguns, é de muito sofrimento e angústia, tanto que os casos de abandono dos clubes por atletas morando longe de casa não são raros. Para os que ficam, essa dificuldade apenas se justifica pela intensidade com que vivem o Projeto de profissionalização e só pode ser compreendida como suportável considerando-se o Processo de ambientação, que implica as mudanças pessoais referentes ao modo de enfrentar o sofrimento. Menos ou mais intenso, o sofrimento vivido nessa dificuldade é essencial à experiência, podendo ser situado pelo seguinte trecho de relato: ... no começo eu sofri muito mesmo. 'Sofri' que eu falo é assim, de saudade mesmo da família, que é difícil você ir embora assim, deixar a família, deixar os amigos, separar desde pequeno (A16).

Deve-se evidenciar a estrutura incondicionalmente emaranhada das unidades de sentido presentes nesta experiência examinada. Se há um sofrimento que deve ser caracterizado como um sacrifício, marcado por uma decisão e esforço de enfrentá-lo, o Projeto de profissionalização é o maior motivo para se viver esse sacrifício afetivo.

\section{Processo de ambientação}

Como o próprio nome sugere, esse é um processo complexo vivido pelos atletas no momento em que chegam ao alojamento e precisam se ambientar com o novo, o que envolve o espaço físico, como acomodações, alimentação, colegas de quarto e time, profissionais do clube, confrontando ilusões, perspectivas, ideias, fantasias, julgamentos, diante de uma realidade que, invariavelmente, apresenta o inesperado e algum estranhamento.

Entre os aspectos empíricos contemplados por essa categoria há aqueles que, apesar de comuns, são vividos de modo bastante diferente pelos atletas, sendo vistos como favoráveis ou desfavoráveis, mas sempre exigindo um novo posicionamento apresentado como uma aprendizagem. Comumente eles relatam o enfrentamento do inesperado e a percepção de uma forçosa necessidade de se tornarem maduros, muito rapidamente, para que consigam se manter nesse contexto. A lista é grande: falta de privacidade, diferença entre as estruturas de alojamentos dos times em que já haviam jogado, dieta rígida, utilização de quartos em dupla, trio ou até com quatro atletas, compartilhamento de banheiro coletivo, o enfrentamento das gozações e chacotas constante entre os atletas, a receptividade dos outros atletas, a possível formação de amizades e companheirismo, o relacionamento proveniente de um cotidiano com atletas da mesma idade usufruindo do mesmo local e da mesma condição, relacionamento com a comissão técnica. $O$ valor que pode ser atribuído a essa situação variará entre as condições reais apresentadas e entre os atletas, ou seja, para uns, há satisfação em alguns desses aspectos, já, para outros, não há nenhum tipo de satisfação em passar por tudo isso, cada um valorando os fatos à sua maneira, conforme são vivenciados. Há também a dificuldade de lidar com pessoas com hábitos distintos, a convivência com regras rígidas e também a alimentação, não semelhante à que estava acostumado em casa, exigindo o que os jogadores referem como "aprendizagem" própria a esse processo de ambientação.

Observe-se um exemplo de como a ambientação pode ser experienciada em sua diversidade:

Foi difícil. Por que até você saber, conbecer o outro, seu parceiro de quarto, como ele vive, as coisas que ele faz, tem que aprender a respeitar, e também aprender a ser respeitado, então até, nesse um mês aí, eu estava conbecendo como é que era o quarto, o pessoal do meu quarto, o pessoal também do alojamento inteiro, eu estava conbecendo. Ai esse primeiro mês foi mais uma adaptação pra conhecer, como é que era cada um, e depois foi só acostumando.[...] A gente tem uma boa amizade, um, sempre, às vezes um está com fome e tem bolacha no quarto ai a gente está sempre se ajudando ali, para não haver um desentendimento, briga, a gente faz. de tudo para não ter essas coisas no nosso quarto. Nosso quarto... a gente é bastante unido no nosso quarto, a gente é mais unido com a gente ali do que com os outros quartos. A gente tem uma união, toda quarta a gente compra pizza, reveza de comprar pizza, a gente... eu trouxe agora uma TV lá, ai cada um respeita o volume essas coisas. Está sendo bacana. (A6)

Assim, o que se está chamando de processo de ambientação corresponde a uma percepção geral do jovem acerca do ambiente em que se situa e que varia 
no tempo. A positividade ou negatividade dessa percepção é bem sintetizada pela intensidade com que o jovem vivencia a experiência do acolhimento no clube. Longe de ser uma abstração afetiva, o acolhimento é um fenômeno correlativo às experiências que o jovem vai vivendo, como a recepção do time para com esse atleta recém-chegado, o respeito ou a falta de respeito recíproco entre os atletas, a divisão, restrição e o acesso à alimentação, a posse e o uso de objetos individuais, sobretudo itens que facilitam a comunicação com o mundo externo ao clube, como notebook, telefones celulares, televisores no quarto e, finalmente, a exploração da nova cidade e daquilo que ela oferece em termos de lazer. Se no processo de ambientação há o acolhimento de um lado, há também, de outro, a modificação de posicionamentos do sujeito conforme lida com o novo, o já mencionado aprendizado. Observe-se o exemplo:

Aprendi a conviver no meio dos garotos lá e tal, porque a gente quando está na casa da gente é uma coisa, agora quando você chega em um convivio aonde tem garoto do Rio de Janeiro, tem do Maranhão, tem num sei onde, é garoto de, vamos dizer assim, origens diferentes e tal. São diferentes os modos de cada um ser, aí você acaba aprendendo a se ambientar, a conviver com cada um de certo jeito (A19).

O trecho seguinte exemplifica a diferença com que uma situação muito semelhante pode ser vivida: "quando eu cheguei eu fiquei muito impressionado com tudo que tinha assim, coisa que eu nunca tinha visto assim, coisa que en não esperava, com a estrutura, nossa, me deu uma euforia que era sem explicação" (A17).

\section{Projeto de profissionalização}

O projeto de profissionalização, como fora mencionado, é a meta essencial à experiência de morar em alojamento, pois, invariavelmente, é a vivência dessa expectativa idealizada que justifica que o atleta passe por todas as adversidades. Isto é, o enfrentamento de todo tipo de sofrimento e dificuldade próprios à experiência se dá em nome da realização do sonho de ser um atleta profissional de futebol. As seguintes passagens deixam evidente o sentido dessa categoria: “... a condição era difícil, precária lá, às vezes faltava até alimentação e era muito difícil, a gente ia mesmo no coração pra chegar, quem sabe realizar o sonho ” (A14); “...não é nada fácil. A gente tem que lutar muito ainda, pra [...] lá na frente [...] chegar no profissional mesmo" (A16).

No momento em que esses jovens relatam as dificuldades diversas e intensas que suportam, evidencia-se a relevância ímpar da vontade que têm de se tornarem jogadores profissionais de futebol. A idealização sobre a profissionalização costuma ser grande. Para muitos, a materialização desse projeto consiste na realização de um sonho. Um dos atletas relata:

eu abri mão... ah sei lá, eu abri mão de bastante coisa pra ficar aqui. Abri mão lá de Dracena que eu tinha... eu tinha uma vida tranquila lá, a gente estudava, podia fazer faculdade, podia fazer tudo. Abri mão pra vim jogar bola, que é uma coisa que eu amo que eu quero fazer. Abri mão de ficar perto da familia também... É difícil, mas é gratificante, a gente vai vendo que vai fazer bem mais pra frente, agora já está fazendo bem, vai fazer bem mais pra frente (A7).

\section{Correr atrás}

A última categoria encontrada diz respeito a todas as outras, pois ela está presente, com a peculiaridade relativa a cada indivíduo entrevistado, como eixo das vivências correspondentes às outras categorias. O nome adotado para esta categoria axial não é ao acaso, mas alude a uma expressão muito usada no cotidiano, seja por atletas, seja por qualquer pessoa que tenha um objetivo claro a ser conquistado.

Essa categoria, como fora mencionado, articula a vivência de todas as outras. Ela se interpõe a todas as precedentes, uma vez que dá margem a todo o julgamento e esforço dos atletas em torno da possível realização do Projeto de profissionalização, abarcando expectativas, audácias, persistências, intenções e planos. Trata-se da resposta pessoal à exigência de seriedade, à dificuldade de sair de casa, ao processo de ambientação, ao projeto, resposta que emerge como atitude, postura e empenho. A todo o momento os atletas relatam essa batalha, essa luta em busca de um sonho, a partir do momento em que decidiram abraçar a meta de se tornar profissionais, fazendo-se presentes em toda essa trajetória. Os atletas também contam que aquilo que antes parecia mais distante vai se tornando a cada dia mais próximo, quase sempre atribuindo a si, ao aperfeiçoamento de seu desempenho e aos próprios esforços essa realização: "É difícil, mas é gratificante, a gente vai vendo que vai fazer bem mais pra frente, agora já está fazendo bem, vai fazer bem mais pra frente" (A7). Correr atrás diz respeito a considerar o peso do sofrimento vivido menor que o da recompensa, a meta almejada. Isto é, considerar positivamente e com tenacidade que a pena é válida, mesmo se excessiva. Mesmo diante da incerteza de que os esforços pessoais serão suficientes para atingirem os objetivos, os jovens compreendem que sem esses esforços não há chance de realização, tendendo a atribuir a si toda a responsabilidade: 
Eu quero virar um jogador profissional. Sei que vou ter que passar dificuldades pra isso, então eu sei, tá difícil aqui, ficar longe da familia, dos seus amigos, é dificil, mas pra quem quer vencer na vida do jeito que eu quero, passar dificuldades eu não quero, mas então eu quero ficar aqui. Falar que está bom, não está. (A1).

Finalmente, ressalta-se que cada categoria apresentada revela uma faceta típica dessa experiência, individualmente variável, mas essencialmente constituída pela tensão vivencial já indicada nas descrições. O conjunto de tensões vivenciais expostas pelas categorias compõe a experiência dos sujeitos da pesquisa.

\section{Discussão}

O objetivo da investigação foi atingido por meio da análise intencional dos relatos colhidos, que individuou as vivências possibilitando compreender a configuração da experiência desses jovens no recorte contextual do presente estudo. Os resultados confirmam que, do ponto de vista experiencial dos atletas, a situação de viver em alojamento designa claramente aqueles traços que a literatura sinaliza como pertinentes à transição de carreira no esporte. Nota-se como, a exemplo do final da carreira profissional do atleta, abordada por Brandão e cols. (2000), esse momento mais inicial da carreira esportiva exige novas adaptações, decisões e julgamentos próprios. Se essa exigência será uma demanda constante durante a carreira, as categorias apresentadas nos resultados constatam as especificidades guardadas por esse momento nesse contexto.

De maneira geral, Barros (2008) aponta que alguns dos fatores marcantes do processo de transição são: suporte social com amigos, família e pessoas significativas para o atleta; experiência proveniente de transições passadas, que geralmente o faz repensar a situação vivida no esporte e que o mantém na categoria de atleta; identificação com a modalidade esportiva, como fator de grande amplitude na trajetória de vida do atleta; e, por fim, a autora cita a situação financeira que o esporte apresenta para o atleta. Descontada a experiência proveniente de transições passadas, praticamente inexistente para esses jovens atletas, nenhum desses fatores deixou de comparecer nos relatos colhidos.

Wylleman, Alfermann e Lavallee (2004) argumentam que assim que os jovens atletas vão se fortificando na profissão, com o passar do tempo, eles se dispersam da sua rede de amizades. Esse tipo de rede é considerada uma fonte primária para iniciação na carreira esportiva entre os jovens. Ou seja, já de início há uma transição marcante: a quebra dessa rede de amizades e a formação de um novo vínculo, uma nova rede. Essa é uma passagem que indica a primeira transição da carreira deste atleta.

Pode-se conferir a proximidade entre o que aqueles autores chamaram de "quebra da rede de amizades" e as categorias denominadas como Dificuldade de estar fora de casa e Processo de ambientação. Porém, entre o fator "quebra da rede de amizades" e a dificuldade e o processo ora descritos, há uma inversão de perspectiva do olhar que passa da pronta objetividade de uma ruptura factual à compreensão de uma experiência que emerge como tensão existencial. Ambas, ruptura e dificuldade/ processo, contemplam o desafio recorrente nesse acontecimento, uma vez que, no mundo do jovem atleta que passa a morar em alojamento, tudo fica diferente do que era, os amigos não estão mais juntos, a família está longe. Mas nada permite prever como essa ruptura objetiva será vivida por cada um. Sem perder de vista que essa ruptura ocasiona uma tensão vivencial, nem se deter nos limites objetivos de um fator, a perspectiva fenomenológica dá um acesso compreensivo, mais próximo à experiência e, portanto, à pessoa do atleta.

De maneira mais afinada com o enfoque compreensivo aqui adotado, Stambulova (1994) alega que, para pensar o processo de transição de carreira para o atleta, é necessário dar luz a sua subjetividade, ao significado do esporte em sua vida, assim como sua experiência esportiva e suas relações vividas nessa modalidade. Por isso, uma transição pode ser uma passagem nada simples e até penosa para alguns, enquanto é algo normal para outros. Em linha com Melhem (2012), a compreensão da transição na vida de um atleta depende de um entendimento do acontecimento, que envolve um grande processo de adaptação, sabendo que neste processo, o esportista tem a necessidade de tomar suas decisões e assumir as responsabilidades dela.

Este ponto é crucial para atletas da categoria sub17, uma vez que, de acordo com Guardini (1987), esses jovens costumeiramente se encontrar em meio a uma turbulência de sentimentos, com a segurança dos pais e do lar já desaparecida, os contatos frequentes com coisas novas, pessoas novas, acontecimentos novos, trazendo o mundo exterior para dentro da "ex-criança", a distinção entre os padrões de comportamentos úteis e nocivos, bem e mal, o foco para objetivos e o esforço para alcançá-los. Assim, essa adaptação e transição pode se tornar uma fase um pouco mais agitada que as demais. A dificuldade de estar fora de casa e a tensão entre 
brincadeira e seriedade são os modos próprios pelos quais o jogador de categoria de base que mora em alojamento vivencia esse aspecto da transição.

Facetas das vivências aqui descritas se encontram com o levantamento de Henriksen, Stambulova e Roessler (2010) de fatores que frequentemente relacionam a situação vivida por jovens atletas, como o gasto excessivo de tempo em atividades da modalidade, a necessidade de fazer amizades no contexto esportivo e a administração das atividades escolares. Esses fatores, ou, em expressão fenomenológica, essas condições empíricas ou fáticas, são algumas das possibilidades reais com que a vivência descrita na categoria processo de ambientação pode se manifestar. A considerar pelo trabalho de Henriksen, Stambulova e Roessler (2010), esses estão entre alguns dos mais frequentes fatores com que os jovens se deparam. Com efeito, diversos trechos de relatos coincidem com estes achados ${ }^{1}$. Em chave fenomenológica, apreender as vivências não significa ir ao encontro de uma abstração, mas delinear um elemento essencial cuja manifestação é múltipla, não se reduz a determinados fatores, mas se vive em acordo com a situação de cada pessoa. É também com relação a essas vivências inescapáveis que, necessariamente, seja de modo deliberado ou não, os jogadores nas condições prescritas assumirão posicionamentos.

Invocando a chamada Teoria da Autodeterminação proposta por Ryan e Deci (2000), Taylor e Bruner (2012) alertam que, entre jogadores jovens das categorias de base de futebol, em equipes de alto rendimento, três demandas psicológicas merecem ser supridas e desenvolvidas. A primeira demanda é autonomia e diz respeito às próprias escolhas e à responsabilidade pelos atos. Nos resultados ora apresentados, a questão da autonomia não comparece como conceito de valor abstraído, nem como fórmula prescritiva, nem como recomendação idealista que se arrisque a meramente anunciar e depositar junto ao atleta o encargo de ser autônomo. Trata-se de questão que, de uma forma ou de outra, atravessa todas as experiências vividas reconhecidas junto aos atletas entrevistados. Todavia, é com relação à tensão entre brincadeira $X$ seriedade que a questão da autonomia se explicita mais abertamente, já que

\footnotetext{
1 Um exemplo ilustrativo é o do trecho transcrito: "Quando você começa a conhecer mais as pessoas, acho que você se sente mais à vontade, ai foi que, quando eu fiquei conbecendo... comecei a conhecer as pessoas lá, eu me senti em casa, me senti à vontade, aí fui me soltando, aí já foi começando a ficar melhor o clima, e tudo começou a ficar melhor pra mim. Ai a relação com eles com o grupo, com todo mundo lá começou a ficar melhor. Ai foi [...] cada vez foi evoluindo cada vez mais, fiquei muito contente" (A18).
}

se joga no balanceamento entre o comprometimento da responsabilidade e espontaneidade lúdica, sendo decisiva nesta etapa, mas constante ao longo da carreira do jogador.

Competência é a segunda demanda, tratando-se de um sentimento de integração social com o meio, levando em conta também sua autoestima, experiências passadas e o grau de reflexão positiva que ele tem da sua própria condição de eficácia. Tanto as vivências referentes à condição de Dificuldade de estar fora de casa como à do Processo de ambientação evidenciam as tensões próprias pelas quais se passa nesse processo de integração com o novo meio. A terceira demanda, de Relacionamento, vem caracterizada como uma conectividade com o meio social. Seu desenvolvimento corresponderia a levar a bom termo os desafios vividos no Processo de ambientação. A relação entre a Teoria da Autoderminação e as vivências ora descritas põe em cena, por um lado, a espessura das tensões próprias à condição desses atletas, por outro, os ideais para solucioná-las. Ter em consideração essa relação dá ao psicólogo os elementos concretos e perspectivos com os quais deverá lidar para promover uma assessoria e acompanhamento psicológicos adequados a este contexto.

Os posicionamentos existenciais descritos e discutidos dão margem à reflexão sobre a atuação do psicólogo no clube de futebol junto às categorias de base. Conforme os resultados sinalizam, este momento e esta condição da transição esportiva consistem em mudanças decisivas para o jovem atleta. A abordagem fenomenológica dá ao psicólogo elementos para intervir com base numa compreensão integral do atleta nesta condição, levando em conta a passagem da vida esportiva na qual se encontra, sua trajetória e suas características pessoais para compreendê-lo como um todo, observando seu horizonte existencial, seu contexto, e sua temporalidade. Isso significa que uma atuação do psicólogo nesta linha não deve nem se prender à faticidade da experiência do atleta, isto é, a fatores empíricos que predominam nesta condição e poderiam ser lidos de modo determinista; nem se projetar de modo idealista com base em valores abstratos prontos. Prender-se à faticidade da condição desses jovens poderia levar à crença de que apenas a oferta de condições ambientais adequadas atenderia às suas necessidades. Projetar-se de modo idealista, por sua vez, conduziria a soluções psicologistas, atribuindo à exigência de virtudes e de força psicológica dos atletas as possíveis soluções para suas dificuldades, a exemplo dos modelos de autoajuda. 
Melhem (2012) observa que o atleta deve ser convidado a fazer a reflexão acerca de si mesmo. Embora a condição de "ser atleta" seja evidenciada como algo passageiro, a autora alerta que o sentido dessa experiência vivenciada pelo atleta o acompanha por toda sua vida. A importância desse momento é decisiva, pois consiste num processo em que o atleta aprenderá novas responsabilidades que, longe de serem facilmente assumidas, implicam contrabalanceá-las com desejos mais imediatos e espontâneos, como descrito na categoria brincadeira $x$ seriedade. Trata-se de enfrentar e desafiar seus medos, isto é, as inevitáveis incertezas referentes aos resultados de suas escolhas, como se apresentam em todas categorias. Uma vez que o desafio, acompanhado de sua responsabilidade inerente, é assumido, trata-se de renová-lo em acordo às sempre inconstantes circunstâncias da vida, o que se coloca como a necessidade e o empenho de correr atrás, algo que será recorrente na vida do atleta.

Entende-se que a falta, contudo, de tudo aquilo que pode ser representado como "lar", equivale à ausência de uma experiência que tem valor intangível para o jovem atleta. Vários dos atletas entrevistados manifestaram que constantemente choravam, principalmente na chegada ao clube, o que lembra que as escolhas feitas e mantidas não os isentam do sofrimento, sobretudo da tristeza motivada por essa ausência. Trata-se da falta do que era rotineiro, cotidiano e habitual, daquilo que afetiva e materialmente lhes dava um conforto na vida familiar e também na familiaridade da vida do dia a dia.

Pelo Processo de ambientação, esses muitos elementos vão ocupando e desocupando a atenção dos atletas em sua vida cotidiana, num processo em que novos valores, novos relacionamentos, novos costumes vão ganhando a familiaridade que lhes proporciona mais estabilidade afetiva e mais confiança em suas próprias escolhas. Que essa ambientação não seja uma regra, e que não necessariamente se passe, é uma das razões para a necessidade de acompanhamento psicológico num clube. Caso, de alguma maneira, a experiência desses jovens não se preencha com novos valores e novos costumes, novas amizades e acolhimento, como acontece no Processo de ambientação, o sofrimento tende a se intensificar, já que a atenção se volta saudosamente para aquilo que era relevante, e passam a posicionar o atleta nesses valores, que antes não se faziam presentes. Todavia, para o atleta, é sem dúvida o valor e o cuidado com o seu objetivo, o Projeto de profissionalização, aquilo que justifica todos os sacrifícios. Como assim?

Já se mencionou que as categorias apresentadas estão entrelaçadas, cabendo ao sentido de correr atrás o nó decisivo que as amarra na experiência de um todo significativo e pessoalmente empenhado na vida do jovem atleta. Nesse sentido, sua formação de identidade de atleta está em questão nessa fase de transição de carreira.

Como tratado na introdução, a identidade, em suma, consiste numa imagem de si a que o sujeito julga corresponder. Pode-se constatar como as vivências individuadas nos resultados preenchem diferentes lugares na distância que há entre a imagem e sua correspondência, isto é, a condição atual do atleta que mora em alojamento de categoria de base e a identidade almejada. Esta última é bem caracterizada pelo Projeto de profissionalização. Se a profissionalização, enquanto projeto, é aquela imagem positiva de si mesmo ainda situada no porvir para a qual o sujeito se lança, a dificuldade de estar fora de casa, o processo de ambientação e a brincadeira versus a seriedade preenchem as distâncias a serem percorridas com vistas à sua realização. Como se viu, para se avizinhar da meta almejada, exige-se empenho, e é nisso que consiste o correr atrás, vivência volitiva que personaliza a maneira pela qual os desafios rumo à profissionalização serão encarados. Não se poderia presumir, portanto, uma forma ideal a essa vivência que sempre se depara com contingências imponderáveis na atuação de um jogador, como a ideia de talento deixa tão evidente. Correr atrás, optar por se empenhar, com seus riscos e sacrifícios, mas também com sua satisfação, mérito e realização, é a responsabilidade à qual não se pode fugir, mesmo quando a opção por se profissionalizar sai de cena, uma vez que o jovem se verá cobrado a empenhar-se em outra atividade.

Os resultados e a discussão deste trabalho mostram como os fatores ou elementos decisivos nessa fase da transição de carreira esportiva se confirmam de modo consistente, quando colocados em diálogo com a literatura. Entretanto, a maneira de abordá-los se diferencia, sinalizando os pressupostos de diferentes perspectivas em psicologia. Nesse sentido, para concluir este trabalho, vale reivindicar a posição em que se situa a psicologia fenomenológica (Mahfoud \& Massimi, 2008, 2013) e, consequentemente, a posição em que a descrição essencial das vivências encontradas (as categorias) toma parte existencialmente junto ao atleta na condição investigada. Reivindicar esse posicionamento significa recusar qualquer interpretação que entenda a consistência dos elementos comuns à literatura como equivalência entre os resultados.

A perspectiva adotada teve em vista o estudo científico da pessoa, numa abordagem qualitativa fundada 
na filosofia. A consequência prática de se adotar uma perspectiva assim corresponde a um trabalho em psicologia que tome a pessoa como centro de sua atenção. Não cabe aqui refazer o sentido conceitual do fenômeno "pessoa" (Mahfoud \& Massimi, 2008), mas pontuar como isso incide nos resultados. Como a pessoa não é separada de seu mundo ambiente, de sua história, de seu projeto, de seu sentimento, de seu entendimento, os resultados da pesquisa descrevem os elementos essenciais que se fazem presentes em sua percepção, ou seja, em sua apreensão e projeção ao mundo. A percepção da pessoa contempla o mundo e é atravessada por sua condição sentimental, o que, quando consistentemente se mostra uma condição correlativa ao mundo que se apresenta, vem descrito como unidade de sentido psicológico, ou seja, elemento essencial da condição estudada. Em outras palavras, o cruzamento intencional permite apreender a consistência dessas experiências vividas levando os resultados a afirmarem não as vivências de certa pessoa nessa condição, mas as vivências da pessoa assim situada.

\section{Considerações finais}

O mundo-da-vida do jovem atleta de futebol morando em clubes, isto é, da pessoa situada nesse ambiente e condições particulares, revela-se uma tensão afetiva e decisiva entre os padecimentos e os valores que as categorias dos resultados procuraram dar conta de descrever. Tratou-se de desvelar as vivências nessa cultura particular, por meio da arqueologia fenomenológica. A pessoa vive essa tensão e não poderia vivê-la como tal fora do ambiente em que está situada. Mais, a pessoa não poderia deixar de viver esta tensão, tal e qual se buscou descrever, estando aí situada. Para o atleta de futebol em categoria de base que mora em alojamento, essa tensão não é uma opção, é ostensiva, impondo-se a necessidade de fazer escolhas que o posicionem com relação a ela.

Não há atleta no alojamento que não vislumbre o Projeto de profissionalização. A força desse projeto pode se atenuar, pode mesmo se apagar diante de adversidades à sua realização, que conduzam o jovem a retirá-lo do horizonte, abandonando-o. Todavia, sem alguma presença do mesmo - seja este um projeto subdimensionado, seja já determinado como meta -, não existe um jovem vivendo no alojamento. $\mathrm{O}$ mesmo se passa com a brincadeira e a seriedade, elementos expressivos de um humor correspondente ao que fazem, o futebol, e ao que vivem, todo o ambiente planejado, bem ou mal, para uma possível profissionalização. Obviamente, sem estar fora de casa, o atleta não se situaria vivendo no alojamento. Estando fora de casa, afetos, valores e costumes familiares deixam de estar efetivamente presentes para os jovens, destacando-se sob o signo da ausência, da falta. Mesmo que possa haver muita coisa positiva em estar fora de casa, o que se destaca no horizonte vivenciado pelo atleta é a dificuldade, sendo esta uma qualidade essencial a essa condição. Novo ambiente, novas relações, nova organização do tempo, do espaço, dos costumes em geral, especialmente os alimentares, afetivamente significativos e por isso muito lembrados: impossível não haver o Processo de ambientação, cuja versão positiva está na receptividade das pessoas no clube, implicando o acolhimento que possibilita fazer dali um ambiente progressivamente familiar. E para que tudo isso se mova e faça sentido, é preciso correr atrás da bola e da meta.

A síntese da análise intencional apresenta como o mundo-da-vida do jogador de futebol de categoria de base morando em alojamento é também o resumo daquilo que pode ser elencado como as principais contribuições do trabalho. Estas contribuições residem numa reorientação da abordagem desta situação específica de transição de carreira esportiva que, com efeito, é sensível à condição existencial do atleta. Isso significa que, sob essa perspectiva, a eventual impessoalidade da enumeração de fatores objetivos que delineiam a condição desse atleta é deslocada junto à esfera experiencial pessoalmente vivida pelo jogador. Essas são as questões existenciais que efetivamente se colocam para o atleta e cujo conhecimento favorece um acompanhamento psicológico adequado e efetivamente orientado. Uma virtude de se ter em mãos a descrição do mundo-da-vida nessa condição é que essa é suficientemente objetiva para acusar aspectos essenciais de sua experiência e, ao mesmo tempo, suficientemente aberta para respeitar a condição subjetiva, portanto, relativa da pessoa de cada jogador.

Um limite do estudo decorre da especificidade do contexto examinado. Pontuados o esporte futebol, os clubes profissionais, a categoria de base, o alojamento em que vivem, o fato de que sejam apenas atletas do sexo masculino; coloca-se em questão o quanto esses resultados poderiam ser transferidos para condições diferenciadas, como outros esportes, outras fases de carreira, outras faixas etárias, atletas do sexo feminino. Novas pesquisas poderiam trazer esclarecimentos, cujo contraste com os resultados ora apresentados ensejaria o desenvolvimento de um modelo de transição de 
carreira esportivo orientado pelo ponto de vista experiencial próprio à psicologia fenomenológica.

\section{Referências}

Ales Bello, A. (1998). Culturas e religiões: uma leitura fenomenológica. (A. Angonese, trad.). Bauru: EDUSC. (Original publicado em 1997).

Amatuzzi, M. M (2001). Por uma psicologia humana. Campinas, SP: Alínea.

Barreira, C. R. A. \& Ranieri, L. P. (2013). Aplicação de contribuições de Edith Stein à sistematização de pesquisa fenomenológica em psicologia: a entrevista como fonte de acesso às vivências. Em: M. Mahfoud, M. Massimi (Org.), Edith Stein e a Psicologia: teoria e pesquisa. Belo Horizonte: Artesã, 2013, 449-466.

Barros, K. S., (2008). Recortes da transição na carreira esportiva. Revista Brasileira de Psicologia do Esporte, 2(1), 1-27.

Brandão, M. R. F., Akel, M. C., Andrade, S. A., Guiselini, M. A. N., Martini, L. A. \& Nastás. M. A. (2000). Causas e consequências da transição de carreira esportiva: uma revisão de literatura. Revista Brasileira Ciência e Movimento, 8(1), 49-58.

Carlin, M. \& Ruiz, G. de L. F. (2012). Transición de Carrera deportiva a um nuevo contexto vital: perspectivas actuales. Cuadernos de Psicologia Del Deporte, 12(1), 103-110.

Costa, A. da S. (2005) Do futebol a uma nova imagem do homem e da sociedade. In Lovisaro, M. \& Lecy, C. N. (Org.), Futebol e sociedade: um olhar transdisciplinar (pp. 13-26.). Rio de Janeiro: EdUERJ.

Guardini, R. (1987). A aceitação de si mesmo, as idades da vida. (Neiva, J. C, trad). São Paulo: Palas Athena.

Henriksen, K., Stambulova, N., \& Roessler, K, K. (2010). Holistic approach to athletic talent development environments: a successful sailing milieu. Psychology of Sport and Exercise, 11(3), 212-222.

Husserl, E. (2006). Idéias para uma fenomenologia pura e para uma filosofia fenomenológica. (M. Suzuki, Trad.). Aparecida: Idéias \& Letras.

Kalrsson, G., \& Sjöberg, L. G. (2009). The experiences of a Guilt and Shame: a phenomenological-psychological study. Human Studies, 32(3), 335-355.
Mahfoud, M. \& Massimi, M. (2008). A pessoa como sujeito da experiência: contribuições da fenomenologia [Versão eletrônica]. Memorandum: Memória e História em Psicologia, 14,52-61.

Mahfoud, M. \& Massimi, M. (Org.). (2013). Edith Stein e a Psicologia: teoria e pesquisa. Belo Horizonte: Artesã.

Maldonato, M. (2014). A subversão do ser: identidade, mundo, tempo, espaço: fenomenologia de uma mutação. (R. Barni e L. Loprete, Trad.). $2^{a}$ ed. São Paulo: Edições SESC.

Melhem, T, X. (2012). O processo de formação de atletas competitivos sob a perspectiva fenomenológico-existencial. (Dissertação de Mestrado), Programa de Educação Física, Universidade de São Paulo, São Paulo.

Nesti, M. (2011). Phenomenology and sports psychology: back to the things themselves! Sport, Ethics and Philosophy, 5(3), 285-296.

Ottoni, G., Ranieri, L. P., \& Barreira, C. R. A. (2008). O posicionamento existencial frente à dor: uma aproximação fenomenológica às experiências de atletas lesionados em tratamento. Revista Brasileira de Psicologia do Esporte, 2(2), 1-32.

Rubio, K. (Org.). (2007). Psicologia do esporte: interfaces, pesquisa e intervenção. São Paulo, SP: Casa do Psicólogo

Ryan, R. M., \& Deci, E. L. (2000). Self-determination theory and the facilitation of intrinsic motivation, social development, and well-being. American-Psychologist, 55(1), 68-78.

Taylor, I. M. \& Bruner, M. W. (2012). The social environment and developmental experiences in elite youth soccer. Psychology of Sport and Exercise, 13(4), 390-396.

Stambulova, N. V. (1994). Developmental sports career investigations in Russia: a post-perestroika analysis. The Sport Psychologist, 8(3), 221-237.

Weinberg, R. S., \& Gould, D. (2008). Fundamentos da psicologia do esporte e do exercício. Porto Alegre: Artmed.

Wylleman, P., Alfermann, D., \& Lavallee, D. (2004). Career transitions in sport: european perspectives. Psychology of Sport and Exercise, 5(1), 7-20.

Recebido em: 17/10/2013

Reformulado em: 26/05/2014 Segunda reformulação em: 15/06/2014

Aprovado em: 04/07/2014 
Sobre os autores:

Rodrigo L. Salomão é psicólogo e estudante de pós graduação lato-sensu em psicologia do esporte, tem interesse pela área acadêmica nos seguintes temas: Fenomenologia, psicologia, psicologia do esporte.

E-mail: rodrigolsalomao@hotmail.com

Giovanna Ottoni é graduanda em Psicologia pela Faculdade de Filosofia, Ciências e Letras de Ribeirão Preto, Universidade de São Paulo. Possui interesse pela área acadêmica, atuando principalmente nos temas: fenomenologia, psicologia, dor, atletas lesionados.

E-mail: gii_cps@yahoo.com.br

Cristiano Roque Antunes Barreira é psicólogo, professor doutor da Escola de Artes, Ciências e Humanidades da Universidade de São Paulo entre 2005 e 2009. Atualmente, é docente da Escola de Educação Física e Esporte de Ribeirão Preto (USP).

E-mail: crisroba@gmail.com

Contato com os autores:

Rodrigo L. Salomão

Av. Claudio Cruz Ribeiro, 2880

Pq. Castelo, Franca, São Paulo, Brasil. 
